\title{
THE INFLUENCE OF INTRAVENOUS ANAESTHETICS ON ENFLURANE-INDUCED CENTRAL NERVOUS SYSTEM SEIZURE ACTIVITY
}

\author{
Paul C. Darmont and Leonard C. Jenkins
}

ENFLURANE is a halogenated ether which has been recently introduced into clinical anaesthetic practice. Its attractive features include rapid induction and emergence, minimal gastro-intestinal disturbance and limited biotransformation. However, sufficient concern exists about its potential for eliciting excitation of the central nervous system (CNS) that the manufacturer considers a pre-existing seizure disorder a contraindication to its use. ${ }^{1}$ Recent reports indicate that enflurane-induced EEG seizures, sometimes accompanied by convulsive activity, may be seen in patients with no apparent pre-existing CNS disorder. ${ }^{2-5}$ Identical EEG seizure patterns can be reproduced in healthy animal preparations. ${ }^{6-9}$ High inspired concentrations of enflurane and/or low carbon dioxide tensions are well established as factors precipitating or augmenting abnormal EEG activity both in man and in laboratory animals.

However, little information is available about the influence on enflurane seizure patterns of other anaesthetic agents used concomitantly. Virtue reported the abolition of enflurane-induced myoclonus in dogs with intravenous thiopentone. ${ }^{12}$ Dobkin and associates noted the absence of motor movements in patients given enflurane in combination with barbiturates and muscle relaxants but, in common with other early clinical evaluations, did not assess these patients for EEG evidence of cerebral irritability. ${ }^{13}$

The study reported here was undertaken, therefore, to assess the effects, if any, of several commonly employed intravenous induction agents on both the threshold for enflurane-induced EEG seizures and on the continuation of established EEG seizure activity.

\section{Methods AND Results}

Eight adult female cats were used for a total of 28 experiments. These animals were chronic preparations with permanently implanted EEG recording electrodes.

Each animal was provided with four stainless steel screws resting on the frontal dura. Subcortical structures were implanted with four bipolar electrodes, corresponding to two bilateral sites. Each animal had two subcortical sites selected from brain stem reticular formation, amygdala or hippocampal nuclei.

Implantation was undertaken with intraperitoneal pentobarbitone anaesthesia $(35 \mathrm{mg} / \mathrm{kg})$. The animals were mounted in a David Kopf stereotaxic apparatus and the subcortical sites were implanted according to the coordinates of Jasper. ${ }^{14}$

From the Department of Anaesthesiology, Faculty of Medicine, University of British Columbia and Vancouver General Hospital. Paul C. Darimont, M.D., F.R.C.P.(C), Clinical Instructor. Leonard C. Jenkins, M.D., C.M., F.R.C.P.(C), Professor and Head, Department of Anaesthesiology, University of British Columbia, Vancouver, B.C. 
The cats were allowed a minimum of two weeks for recovery before studies were undertaken, and a minimum of four days between successive experiments. Accuracy of subcortical placement was verified histologically in randomly selected animals.

The tracheae of the experimental animals were intubated after a single dose of decamenthonium $(0.3 \mathrm{mg} / \mathrm{kg})$ and they were ventilated with a Harvard animal pump. The electroencephalogram (EEG) and lead II electrocardiogram (EKG) were recorded using a Grass model 6 electroencephalograph. An intravenous infusion of 5 per cent dextrose in water was given at $20 \mathrm{ml} / \mathrm{hr}$ during each experiment. Rectal temperature was maintained between $36^{\circ}$ and $38^{\circ} \mathrm{C}$.

The animals were divided into two experimental groups.

\section{Group I}

Six animals were used for a total of 12 experiments to determine threshold changes of enflurane-induced EEG seizures before and after parenteral Diazepam administration.

Enflurane was administered with a Cyprane vaporizer, calibrated for enflurane, and using a fresh gas flow of 3 litre/min of oxygen in a non-rebreathing system. A femoral artery was cannulated in all animals and ventilation was adjusted at the beginning of each experiment to achieve one of three constant $\mathrm{Pa}_{\mathrm{CO}_{2}}$ levels ${ }^{*}\left(\mathrm{~Pa}_{\mathrm{CO}_{2}}\right.$ $20 \pm 3 \mathrm{~mm} \mathrm{Hg}$., $\mathrm{Pa}_{\mathrm{CO}_{2}} 30 \pm \mathrm{mm} \mathrm{Hg}$., $\mathrm{Pa}_{\mathrm{CO}_{2}} 40 \pm 3 \mathrm{~mm} \mathrm{Hg}$ ). Arterial pressure was recorded continuously using a Statham Model P23 pressure transducer and an Electronics for Medicine polygraph.

Spike or spike-wave activity $(>400 \mathrm{~m} . v$.) was recorded at progressively increased inspired enflurane concentrations. Twenty minutes of anaesthesia elapsed at each inspired level before a measurement was made. This time period, based on the enflurane uptake curve, ${ }^{15}$ provided reasonable steady state conditions. Measurement of spike frequencies at each inspired enflurane level was repeated after administration of intravenous diazepam $(1.5 \mathrm{mg} / \mathrm{kg})$. This allowed each animal to act as its own control. Four experiments were used at each of the hypocapneic, normocapneic, and hypercapneic ventilatory levels.

Enflurane seizure threshold decreased with a reduction in $\mathrm{Pa}_{\mathrm{CO}_{2}}$ (Figure 1). Diazepam lowered seizure threshold at each $\mathrm{Pa}_{\mathrm{CO}_{2}}$ level, but this effect was particularly evident at low $\mathrm{Pa}_{\mathrm{CO}_{2}}$ (Figure 2( $\left.\mathrm{a}, \mathrm{b}, \mathrm{c}\right)$ ).

Only one cat displayed motor activity. This animal was hypocapneic and had minor facial and forelimb muscle twitching at a 1.5 per cent inspired enflurane level. Twitching was not seen again at the same enflurane anaesthetic level after diazepam administration.

\section{Group II}

Four cats were used for a total of 16 experiments. Anaesthesia was induced as in Group I animals. The enflurane concentration (approximately 1.5 per cent) and ventilatory pattern were adjusted at the beginning of each experiment to the level at which the EEG displayed only the earliest signs of irritability, i.e. isolated sub-

'Normal Paco $\mathrm{P}_{2}$ in cats (awake) $28 \pm 4.1 \mathrm{~mm} \mathrm{Hg}$ (Fink, B.R., Proc. Soc. Exp. Biol. 112: 328, 1963). 


\section{EFFECTS OF $\mathrm{P}_{\mathrm{CO}_{2}}$ TENSION ON ENFLURANE EEG SPIKE FREQ.}

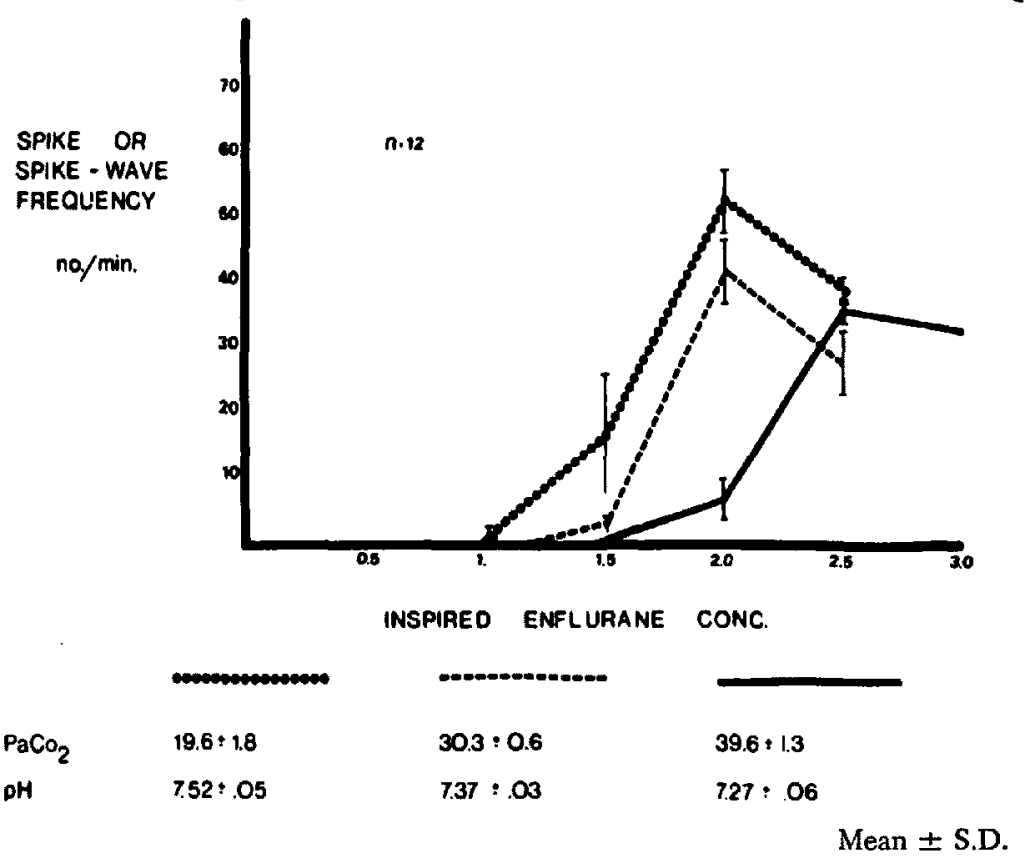

Ficure 1. Note changes in spike threshold and frequency at different $\mathrm{Paco}_{2}$ levels. The declining spike frequency at higher inspired enflurane levels occurs because of increasing periods of interburst suppression.

\section{EFFECTS OF DIAZEPAM (iv) ON ENFLURANE EEG SPIKE FREQ.}

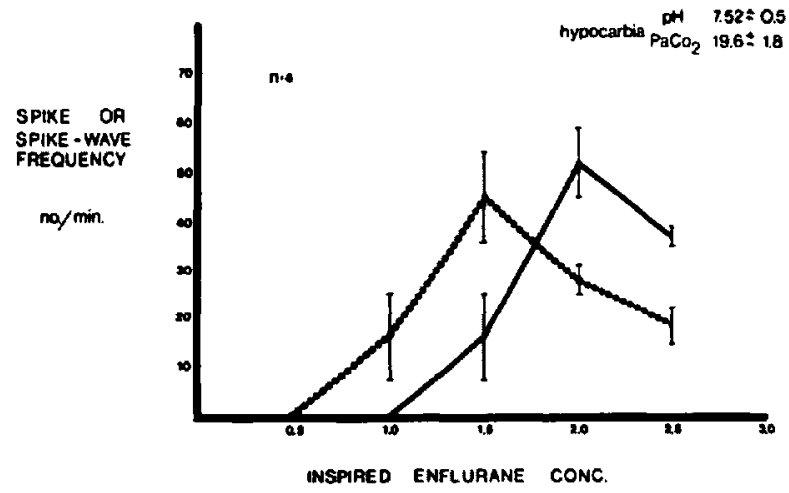

Entlurene atone

Enllurane with Diazepam $1.5 \mathrm{mg} / \mathrm{kg}$.

Ficure 2(a)

$$
\text { Mean } \pm \text { S.D. }
$$

Figure 2( $\mathrm{a}, \mathrm{b}, \mathrm{c})$. Note spike threshold is decreased with diazepam at each Pacos level, but the effects of diazepam appear greatest at hypocarbic levels of $\mathrm{CO}_{2}$. Spike or spike-wave frequency is recorded at hippocampal or cortical recording sites, whichever is greater. The declining spike frequency at higher inspired enflurane levels occurs because of increasing periods of interburst suppression. 
EFFECTS OF IV DIAZEPAM ON ENFLURANE EEG SPIKE FREQ.

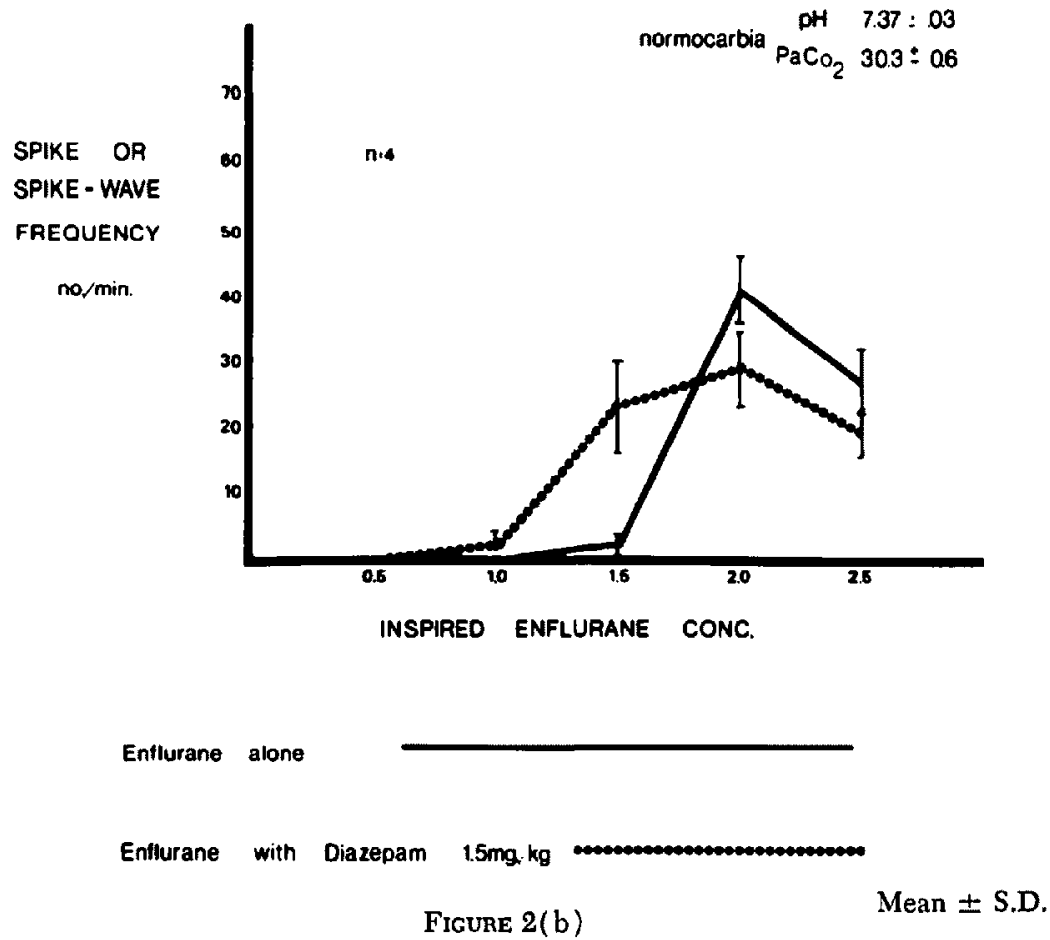

EFFECTS OF IV DIAZEPAM ON ENFLURANE EEG SPIKE FREQ. hypercarbia $\begin{array}{cr}\mathrm{pH} & 7.27: 06 \\ \mathrm{PaCO}_{2} & 39.6: 1.3\end{array}$

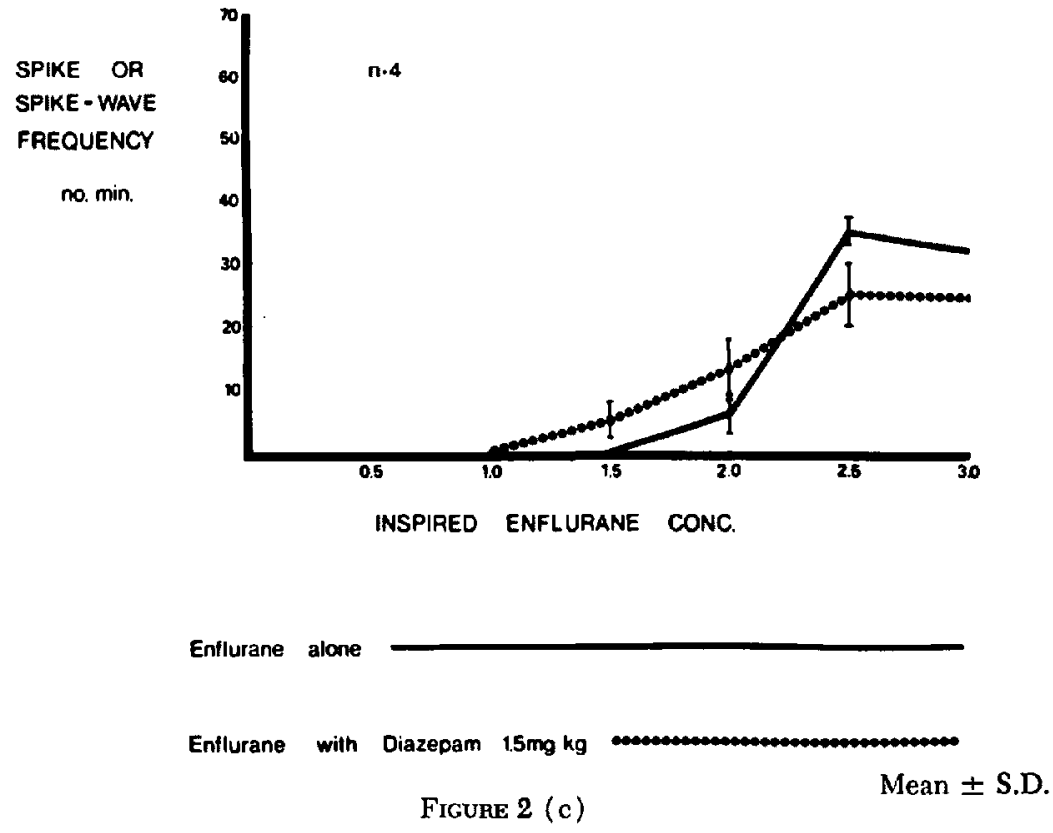


TABLE I

Summary of Intravenous Agents Administered IN Group II ANIMALS

\begin{tabular}{lcc}
\hline \multicolumn{1}{c}{ Drug } & Dose (I.V.) & $\begin{array}{c}\text { No. of } \\
\text { experiments }\end{array}$ \\
\hline $\begin{array}{l}\text { Diazepam } \\
\text { Diazepam solvent }-40 \%\end{array}$ & $1.5 \mathrm{mg} / \mathrm{kg}$ & 3 \\
propylene glycol, $1.5 \%$ benzyl & & \\
alcohol, 10\% ethyl alcohol, & & 1 \\
$5 \%$ sodium benzoate & & 2 \\
Thiopentone & $4 \mathrm{~mm} / \mathrm{kg}$ & 2 \\
& $20 \mathrm{mg} / \mathrm{kg}$ & 2 \\
Methohexitone & $2 \mathrm{mg} / \mathrm{kg}$ & 2 \\
Ketamine & $5 \mathrm{mg} / \mathrm{kg}$ & 3 \\
Ketamine solvent & $5 \mathrm{mg} / \mathrm{kg}$ & 1 \\
Benzothonium Cl. $1: 10000$ & & 16 \\
\hline
\end{tabular}

\section{ENFLURANE AND THIOPENTAL}
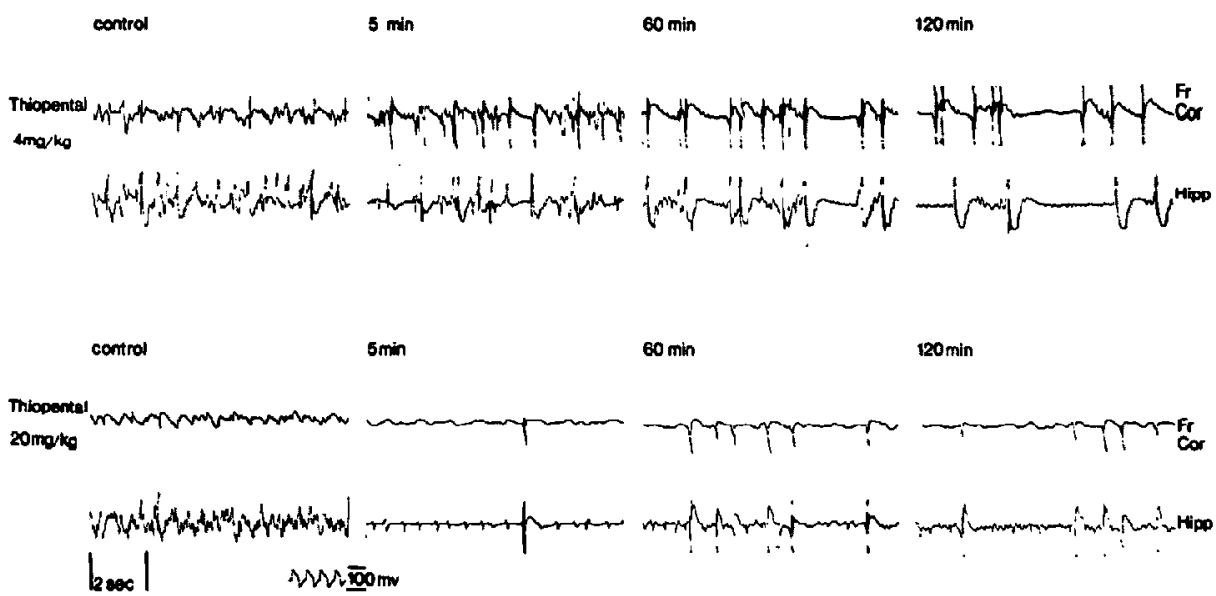

Frgure 3. Thiopentone converts isolated subcortical spiking to complex spike-wave forms synchronous at all recording sites. Periods of interburst suppression are longest after administration of anaesthetic doses of thiopentone. Spike-wave activity is never abolished even with the larger barbiturate dosage. Only two of six recording sites in each animal are represented in the tracings shown.

cortical spikes without cortical synchrony. Once this EEG pattern was reached, no further adjustment was made. One hour of EEG stabilization elapsed before any drug was administered. At least one animal in each drug group had femoral artery cannulization for periodic blood gas monitoring (Radiometer). A summary of the drugs injected appears on Table I. Hyperventilation $\left(\mathrm{Pa}_{\mathrm{CO}_{2}} 20 \pm 3 \mathrm{~mm} \mathrm{Hg}\right)$ was used in all experiments.

Observations on evolving patterns of CNS irritability were made with particular reference to progression of isolated subcortical spiking to synchronous spiking at all recording areas and evolution of simple spike to complex spike-wave forms and 
ENFLURANE AND METHOHEXITAL
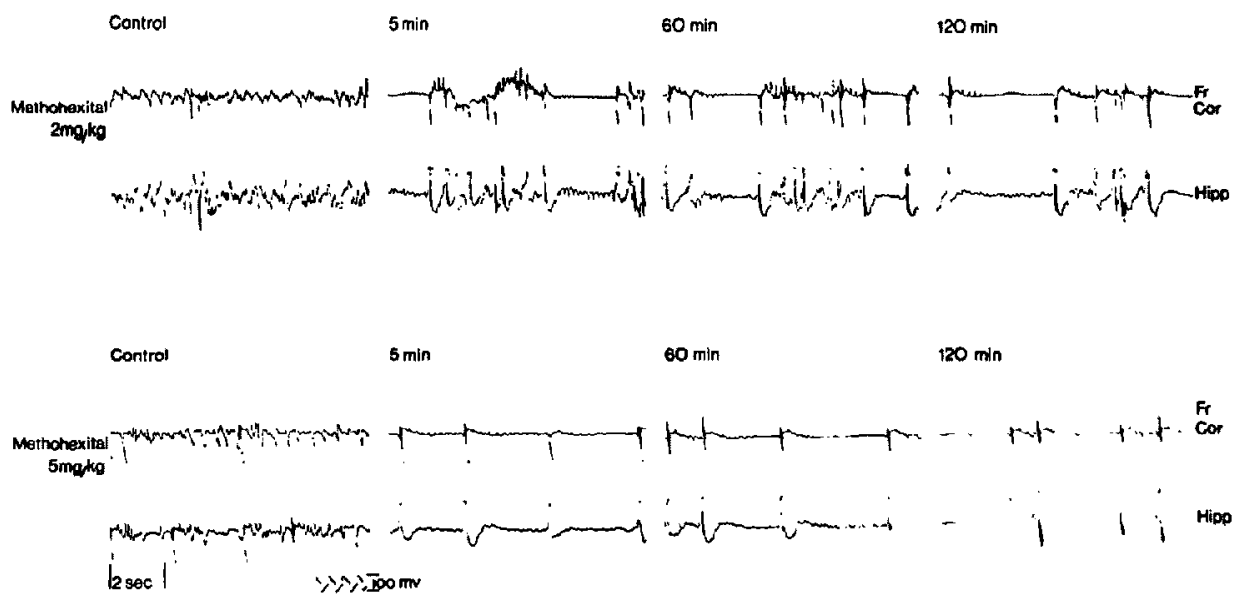

Figure 4. Methohexitone converts isolated subcortical spiking to complex spike-wave forms simultaneously at all recording sites. Periods of interburst suppression occur with administration of anaesthetic doses of methohexitone. Spike wave activity is never abolished even with the larger barbiturate dose. There is no apparent difference in the EEG effects of equipotent doses of thiopentone or methohexitone. Only two of six recording sites in each animal are represented in the tracings shown.

\section{ENFLURANE AND DIAZEPAM}

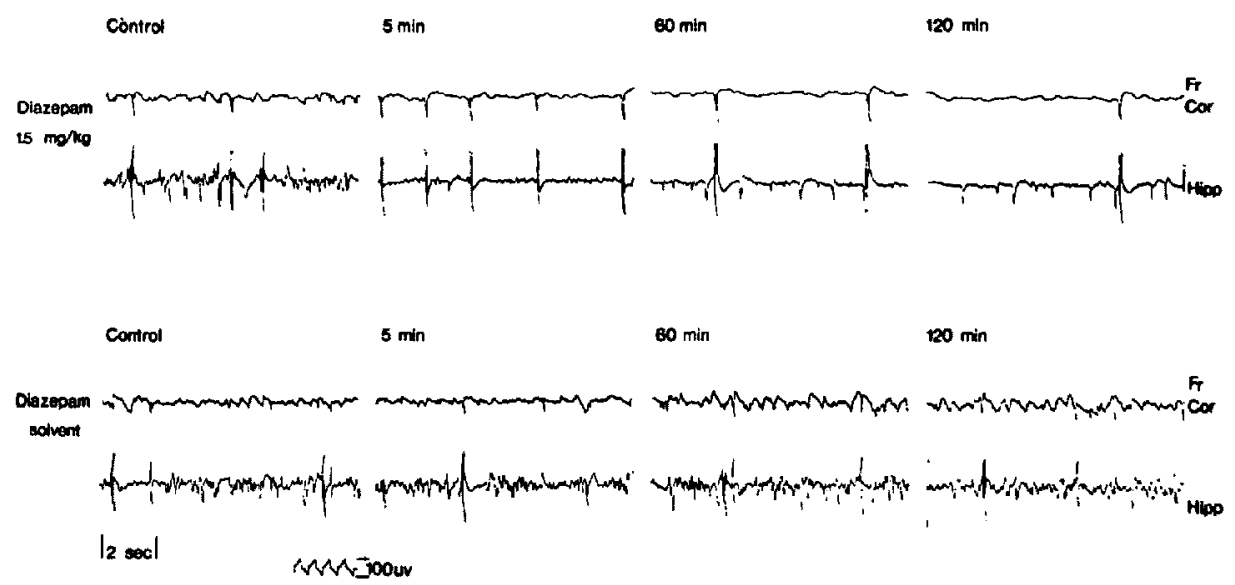

Figure 5. Diazepam converts isolated subcortical spiking to complex spike-wave forms simultaneously in all recording sites. There is no change in EEG pattern after diazepam solvent. Tracings shown represent only two of the six recording sites in each animal.

to spike-wave forms accompanied by periods of interictal burst suppression. No attempt was made to quantify spike pattern frequencies. Representative tracings are shown in Figures 3-6.

All the agents administered converted isolated subcortical spiking activity into synchronous spike-wave forms at all recording sites. The interspike EEG activity was reduced and periods of interburst suppression became prominent. The EEG 


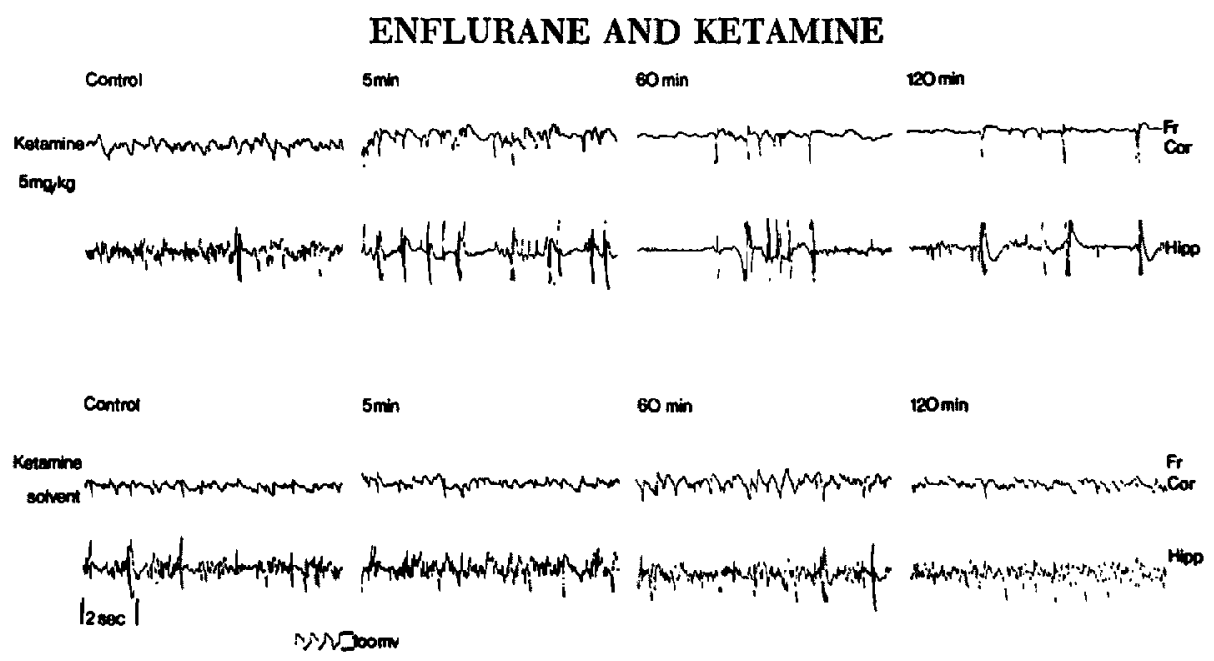

Figure 6. Ketamine converts isolated subcortical spiking to complex spike wave forms simultaneously at all recording sites. Spike or spike wave frequency appears increased. Ketamine solvent had no effect on enflurance EEG pattern. Only two of six recording sites in each animal are represented in the tracings shown.

progression induced by these agents was similar to that obtained by increasing enflurane concentration alone. Spike activity was never abolished, even with the highest doses of barbiturates.

This new level of EEG activity persisted in all animals for at least two hours, regardless of the agent used. This was the limit of our observation period. Spikewaves with interburst suppression has been reported to be the EEG pattern associated with motor movement in cats. ${ }^{6}$ No motor activity was seen in any animal in this group, so the phenomena observed in our series are confined to the EEG seizure patterns.

\section{Discussion}

Guedel's original staging of anaesthesia as a progressive reversible depression of neuronal activity has received critical comment in recent years. ${ }^{16-19}$

- Based on their shared neuropharmacological actions, Winters suggests that anaesthetic agents might better be categorized on the basis of their position in a bidirectional scheme of CNS excitation and CNS depression (Figure 7). Indeed, certain pharmacological agents appear capable of producing the anaesthetic state, that is amnesia and a reduced responsiveness to pain during a state of CNS excitation. ${ }^{10-18}$ Furthermore, this state of excitation can be viewed as a continuum of EEG patterns with fairly specific behavioural correlates (Figure 8). Thus, there appears to be an association between 2 to 3 cycles per second EEG hypersynchrony and hallucinosis, between spike and wave EEG patterns and myoclonic activity and between sustained generalized polyspike EEG discharge and massive tonicclonic convulsions. ${ }^{17}$

Ketamine and enflurane, as well as other anaesthetic agents (gamma-hydroxy butyrate, phencyclidine) produce virtually identical electrical activity as measured 


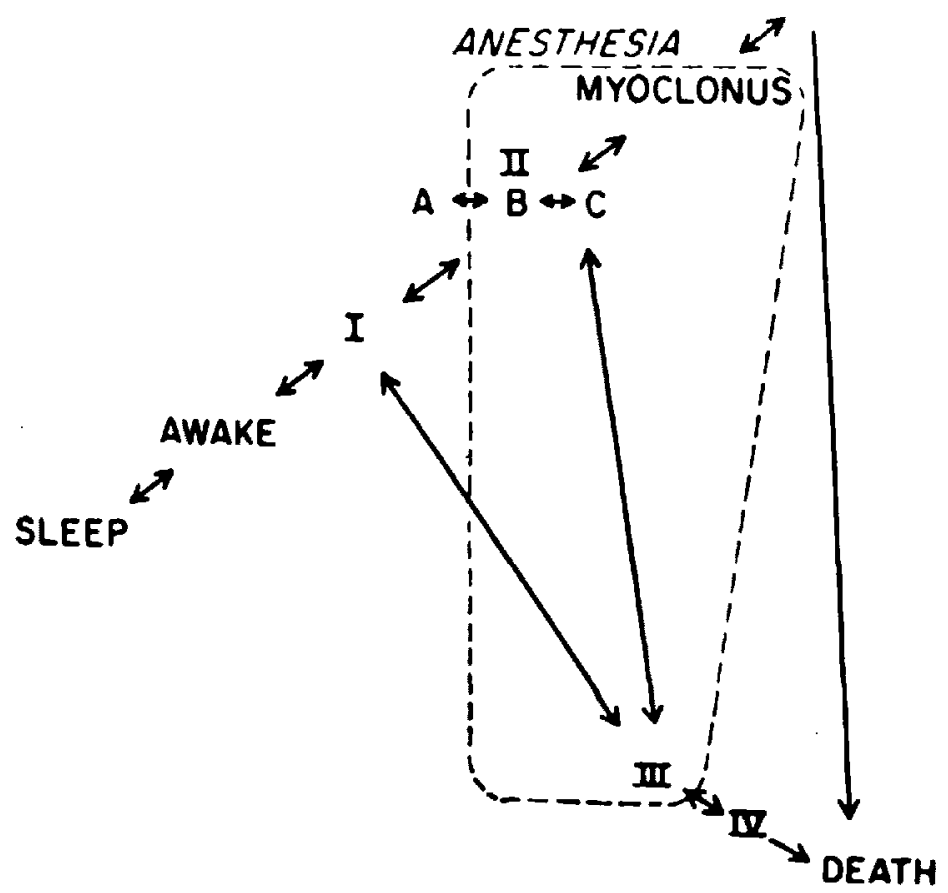

Ficure 7. A proposed bidirectional schema of anaesthetic states (see text for explanation) (from Winters, W.D., et al. Neuropharmacology 11: 303 (1972).

by spontaneous EEG pattern, evoked potential responses, and unit cell activity, but differ in the degree of CNS hyperexcitability and behavioural disorganization produced.

EEG hyperexcitability induced by enflurane, while generalized in its cortical expression, does not appear to cause massive tonic-clonic convulsions in normal man or in laboratory animals. Enflurane seizure patterns bear a closer resemblance to minor motor seizures. Clinical variants of minor motor seizures, of which petit mal or petit mal myoclonus are but two of a group, share with enflurane the characteristics of 2 to 3 cycles per second EEG hypersynchrony (Figure 8), mild and brief myoclonic movements of facial and neck musculature and seizure activation by hyperventilation.

Gastaut $^{34}$ described certain minor motor seizures as being centrencephalic in origin. This designation remains conceptual rather than specific in the pathogenesis of seizure patterns. However, it is useful to consider it to illustrate the interaction of inhibitory and excitatory neuronal pathways on overall central nervous system activity (Figure 9 ).

Certain midline thalamic nuclei act as relay stations for incoming stimuli from all areas of the central and peripheral nervous system. Thalamic discharges are projected diffusely to neocortex and to the limbic system. Excessive discharge within this subcortical neuronal pool is reflected by 10 to 15 cycles per second hypersynchronous recruiting discharge in neocortex and limbic areas. We have noted re- 
(I) EXCITED

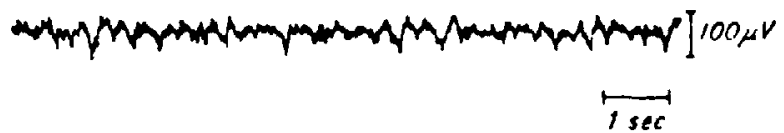

(II)

HALLUCINATORY

II A

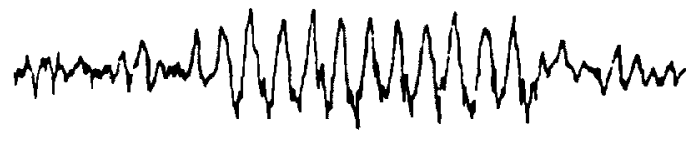

II $B$

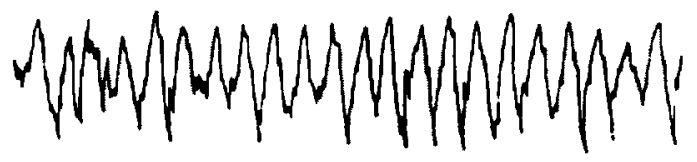

II C

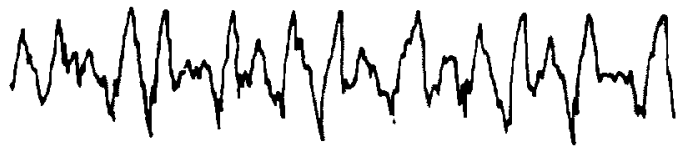

MYOCLONUS PRESEIZURE

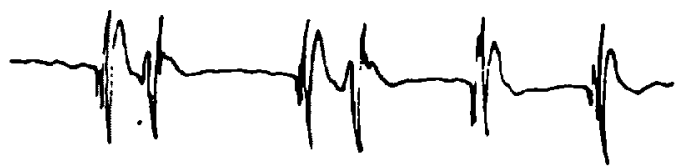

SEIZURE

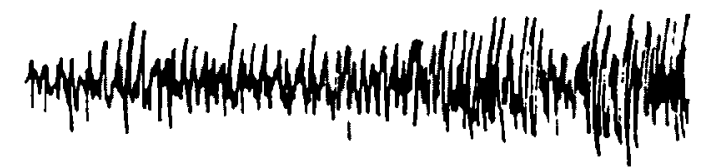

Frgure 8. The corresponding EEG patterns induced by agents causing CNS excitation (stage II) (from Winters, W.D., et al. Neuropharmacology 11: 303 (1972).

cruiting discharge early in the induction phase of enflurane anaesthesia in our animals (Figure 9). It is suggested that thalamic recruiting discharges secondarily activate a thalamo-caudate inhibitory system. ${ }^{34}$ This positive feedback loop, depending on its effectiveness, limits the recruiting response and is reflected in the cortical EEG by a slow wave pattern. Thus, spike wave forms are generated. If a slow wave follows several recruiting spikes, then brief periods of myoclonic activity accompany the polyspike-wave form. This is an EEG pattern frequently recorded with surgical levels of enflurane (Figure 9).

Using deep recording techniques, several investigators have shown that enflurane is unique when compared to other volatile anaesthetic agents such as halothane and methoxyflurane in inducing hyperexcitability within this centrencephalic neuronal pool with increasing concentrations of anaesthetic agent. ${ }^{7,9}$

The centrencephalic recruiting system is believed to receive inhibitory input from other areas, including regions of the brain stem reticular formation. These ascending inhibitory pathways are believed to be selectively impeded with small doses of barbiturates. ${ }^{20-22}$

This "release" phenomenon (by barbiturates) on inhibitory systems is a recognized clinical tool for eliciting latent epilepsy. ${ }^{11,34}$ Barbiturate treatment of petit mal may exacerbate or convert petit mal to grand mal. ${ }^{23,24}$ Small doses of methohexitone ( $40 \mathrm{mg}$ intravenously) may precipitate psychomotor and petit mal epi- 


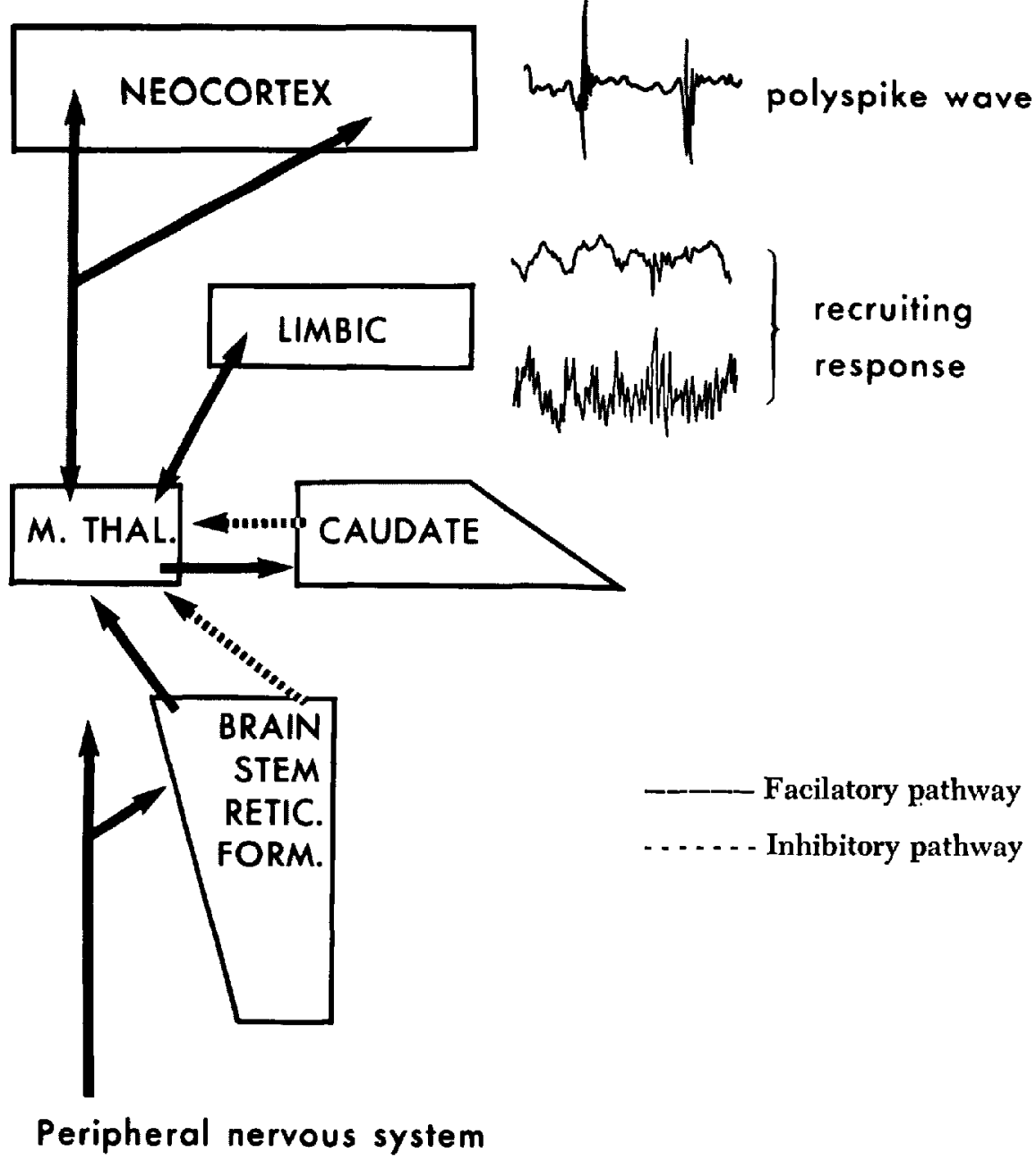

FIGURE 9. A schematic drawing illustrating the pathophysiology of generalized seizures with a hypersynchronous discharge. See text for explanation (adapted from Gastaut, $H$. and Broughton, R. epileptic seizures: clinical and electrographic features, diagnosis and treatment. 1st ed. Charles C. Thomas, Springfield, Ill. U.S.A. (1972).

lepsy when the stimulus of hyperventilation is ineffectual. ${ }^{24}$ In fact, methohexitone has been known to provoke seizures de novo. ${ }^{25}$

In this light, it seems reasonable to demonstrate that early manifestations of enflurane EEG seizure activity may be altered by acute barbiturate administration. In our series, both subanaesthetic and anaesthetic doses of barbiturate appear to augment established enflurane-induced hyperexcitability. Furthermore, this effect persisted during steady state anaesthesia for at least two hours after a single intravenous injection. This time interval exceeds the anticipated duration of action based on plasma half-life, ${ }^{23}$ autoradiographic studies of brain distribution, ${ }^{23,26}$ and specific EEG effects of the barbiturate itself. ${ }^{24}$

Significant hypotension ( $55 \mathrm{~mm} \mathrm{Hg}$ mean) was seen in our series only when 
anaesthetic doses of barbiturate were used. Yet the EEG seizure pattern was enhanced regardless of barbiturate dosage, although periods of interictal burst suppression were longer with anaesthetic doses. We noted no difference in the awakening times of animals receiving enflurane anaesthesia alone, or in combination with barbiturates.

Diazepam, given in subanaesthetic doses $(1.5 \mathrm{mg} / \mathrm{kg})$ during steady state enflurane anaesthesia also augmented established seizure patterns (i.e. converted isolated subcortical spiking activity into diffuse, synchronous spike and wave discharge in cortical and limbic recording sites). This may not be surprising in view of the evidence that diazepam alone produces fast wave EEG Beta activity similar to barbiturate spindlings. ${ }^{27}$ Furthermore, diazepam $(<2 \mathrm{mg} / \mathrm{kg}$ ) given to unanaesthetized cats causes restlessness and high amplitude spiking in the hippocampus. ${ }^{28}$

The effects of diazepam in treating epilepsy remain uncertain. Benzodiazepines are considered successful in approximately 50 per cent of cases, but control is often transient. $^{34}$ Nitrazepam, closely related to diazepam in structure and reported useful in infantile hypsarrhythmia, may trigger grand mal seizures in these patients and may aggravate previously existing petit mal states in others. ${ }^{34}$

The potentiation of enflurane seizure activity by ketamine appears similar to that produced by barbiturates and diazepam, both as to degree and duration. However, ketamine, given alone, appears to excite many subcortical sites. EEG patterns are similar to those produced by enflurane.$^{18}$ However, as with barbiturates, the altered enflurane seizure pattern persisted for a period exceeding the EEG effects of ketamine alone. ${ }^{29}$

One must differentiate between EEG seizure patterns and convulsive activity. Anticonvulsants may abolish motor expression yet leave EEG seizure patterns unaltered ${ }^{34}$ Fewer than 10 per cent of our animals displayed any motor manifestations during enflurane anaesthesia, either spontaneously or subsequent to auditory stimulus. This is less frequent than reported in a similar series of cats. ${ }^{6}$ We noticed no motor activity at all in cats receiving barbiturate, diazepam or ketamine during enflurane administration. The relative poverty of associated convulsive movement may be a manifestation of the neuromuscular blocking properties of enflurane, ${ }^{30}$ rather than due to its specific pattern of central excitation. That question remains unanswered, but another which should be asked is whether sustained epileptoid activity as seen by the EEG is harmful to a patient given enflurane for a prolonged surgical procedure. Wollman in human volunteers ${ }^{31}$ and Michenfelder working with dogs $^{32}$ were unable to find any evidence of compromised cerebal oxygenation.

A systematic attempt to assess whether enflurane seizure activity induces central nervous system functional change in the postoperative period has not been done. Most clinical observations indicate that recovery is devoid of any unusual behavioural responses. ${ }^{5}$

There is a recent report of delayed seizure activity in two patients given enflurane anaesthesia. However, the clinical history and circumstances in these cases would appear to be incomplete. ${ }^{4}$ Julien and Kavan were able to show abnormal EEG spike activity, accompanied by bizarre behavioural changes, in a cat population up to 16 days after a single enflurane exposure.$^{9}$ The possibility of enflurane 
producing post-operative EEG abnormalitiese and/or behavioural dysfunction would appear to need further study.

\section{Summary of Results}

This study assesses the effects of agents commonly used in anaesthesia on enflurane-induced seizure threshold and on established seizure activity, during steady state enflurane anaesthesia. EEG seizure activity was monitored in cats from chronic cortical and subcortical recording sites.

Diazepam, thiopentone, methohexitone and ketamine all enhanced established EEG seizure activity. Diazepam also appeared to lower seizure threshold to an enflurane challenge. This latter effect was most evident under conditions of lowered $\mathrm{Pa}_{\mathrm{CO}_{2}}$. The effects of these intravenous agents on established enflurane seizure patterns exceeded in duration the expected EEG effect of the agent when used alone. The limited number of experiments, however, precluded statistical verification of our findings.

The similarities between centrencephalic minor motor seizures and enflurane seizure pattern in terms of EEG and convulsive expression, including drug response, are noted.

\section{Clinical Implications}

We suggest that these findings warrant further examination of pharmacological and physiological factors which might modify the CNS-exciting potential of enflurane. In the interim, we agree with others that use of enflurane should be avoided where anaesthetic practice demands a hypocarbic technique. ${ }^{32}$

Enflurane should also be avoided in patients with pre-existing convulsive disorders. Careful consideration should be given to its use in the larger patient population who may be considered at risk in developing major seizure manifestations with an enflurane challenge. This group includes children under three years of age with febrile illnesses, patients with closed head injuries - recent or remote, ${ }^{33}$ and family members of epileptic individuals, a proportion of whom inherit the centrencephalic EEG trait with an enhanced epileptic predisposition. ${ }^{34}$

Our experiences would suggest that barbiturate or benzodiazepine administration as acute treatment of enflurane-induced seizure activity is unlikely to be effective in abolishing the EEG manifestations of cerebral discharge. A preferable course of action would be to correct any existing hypocapnoea and to alter technique to reduce or eliminate enflurane from the inspired gas mixture.

\section{RÉSUMÉ}

Il est connu que l'enflurane peut provoquer l'apparition sur l'électroencéphalogramme de tracés épileptoïdes. Ce travail évalue d'une part les effets d'agents anesthésiques d'usage intraveineux couramment employés en anesthésie sur le seuil d'apparition de ces manifestations et d'autre part étudie aussi leurs effets sur un tracé épileptoïde déjà engendré par une anesthésie à l'enflurane maintenue à une profondeur uniforme. 
Le diazepam, le thiopental, le méthohexital et la kétamine, tous les quatre, accentuent l'activité électro-encéphalique épileptoïde déjà présente. De plus, le diazepam semble abaisser le seuil d'apparition de cette activité déclenchée par l'enflurane, phénomène particulièrement marqué en présence d'hypocapnie. Les effets de ces agents intraveineux sur les tracés épileptoïdes déjà existants dépassent en durée les effets intrinsèques de ces agents, employés seuls, sur l'électro-encéphalogramme. Le nombre limité de nos expériences nous interdit la confirmation statistique de ces données.

On fait le rapprochement en cours de route entre l'épilepsie partielle type moteur d'origine centro-encéphalique et le modèle épileptoïde à l'enflurane aux plans de l'électro-encéphalogramme, des manifestations convulsives et de la réponse aux médicaments.

\section{Application clinique}

Nous proposons que ces données justifient un examen plus poussé de facteurs pharmacologiques et physiologiques qui permettraient de modifier cette action neurostimulante de l'enflurane.

Pour le moment nous souscrivons avec d'autres à la recommandation d'éviter l'enflurane là où on recommande lutilisation de l'hypocapnie.

De même l'enflurane est à proscrire chez des malades que l'on sait porteurs de maladie convulsive. De même, doit-on user de prudence chez tous les malades dont on soupçonne quils pourraient présenter des convulsions une fois provoqués par l'enflurane; ce groupe comprend: des enfants de moins de trois ans en pleine fébrilité, des traumatisés du crâne, que le traumatisme soit récent ou non, et les parents proches d'individus épileptiques dont une partie porte le gêne de prédisposition à l'épilepsie.

Nos expériences laissent penser qu'un traitement aux barbituriques ou au benzodiazépine serait inefficace pour abolir les manifestations électro-encéphalographiques épileptoïdes de l'enflurane. Il serait préférable, en ces circonstances, de corriger l'hypocapnie s'il y a lieu et/ou de modifier la technique d'anesthésie en réduisant les concentrations ou en éliminant purement et simplement l'enflurane.

\section{ACKNOWLEDGMENTS}

We would like to thank Miss C. Melton for valuable technical assistance, and Dr. H.D. Sanders for advice in preparing this manuscript.

This work was financed in part by grants-in-aid from the Burroughs Wellcome Company (Canada), Poulenc Limited of Montreal and Abbott Laboratories.

\section{REFERENCES}

1. Enflurane package insert, Ohio Medical Products Canada (1975).

2. Botty, C., Bhown, B., Stanl.ex, V., \& Stephen, C.R. Clinical experiences with compound 347, a halogenated anaesthetic compound. Anaesthesia and Analgesia 47: 499 (1968).

3. Burchiel, K.J., Stockard, J.J., Myens, R.R., Smith, N.T., \& Calverley, R.K. Epileptogenicity of enflurane and isoflurance in man and cats: relative effects of $\mathrm{Pacos}_{3}$ on intersuppression activity and seizure duration. Abstracts of Scientific Papers, ASA annual meetings, Washington, D.C., p. 159 (October 1974). 
4. Ohm, W.W., Cullen, B.F., Amory, D.W., \& Kennedy, R.D. Delayed activity following Enflurane anaesthesia. Anaesthesiology 42: 367 (1975).

5. Linde, H.W., Lamb, V.E., Quimby, C.W., Homi, J., \& Eckenhoff, J.E. The search for better anaesthetic agents: clinical investigation of ethrane. Anaesthesiology 32: 555 (1970).

6. DE Jong, R.H. \& Heavner, J.F. Correlation of the Ethrane electroencephalogram with motor activity in cats. Anaesthesiology 35: 474 (1971).

7. Kavan, E.M., Julien, R.M., \& Lucero, J.J. Electrographic alterations induced in limbic and sensory systems during induction of anaesthesia with halothane, methoxyflurane, diethyl ether, and enflurane. British J. of Anaesthesia 44: 1234 (1972).

8. Julien, R.M. \& Kavan, E.M. Electrographic studies of a new volatile anaesthetic agent: enflurane (ethrane). J. of Pharmacology and Experimental Therapeutics 183: 393 (1972).

9. Julien, R.M., Kavan, E.M., \& Elliotr, H.W. Effects of volatile anaesthetic agents on EEG activity recorded in limbic and sensory systems. Canad. Anaesth. Soc. J. 19: 263 (1972).

10. NEIGK, J.L., Garman, J.K., \& HaHP, J.R. The electroencephalographic pattern during anaesthesia with ethrane: effects of depth of anaesthesia, $\mathrm{Paco}_{2}$ and nitrous oxide. Anaesthesiology 35: 482 (1971).

11. Lebowitz, M.H., Blitr, C.D., \& Dillon, J.B. Enflurance-induced central nervous system excitation and its relation to carbon dioxide tension. Anaesthesia and Analgesia 51:355 (1972).

12. Virtue, R.W., Lund, L.O., Phelps, M. (Jr,), Vogel, J.H.K., Beckitt, H., \& Heron, M. Difluromethyl 1,1,2-trifluro-2-clorethyl ether as an anaesthetic agent: results with dogs and a preliminary note on observations in man. Canad. Anaesth. Soc. J. 13: 233 (1966).

13. Dobkin, A.B., Heinrich, R.G., Israel, J.S., Levy, A.A., Neville, J.R., \& Ounkasem, K. Clinical and laboratory evaluation of a new inhalation agent: Compound $347\left(\mathrm{CHF}_{2}-\mathrm{O}-\right.$ $\mathrm{CF}_{2}-\mathrm{CHFCl}$ ). Anaesthesiology 29: 275 (1968).

14. Jasper, H.H. \& AJMone-Marsan, C.A. Stereotaxic atlas of the diecephalon of the cat. Publ. Nat. Res. Council of Canada (1956).

15. Torm, G., Damia, G., Fabrani, M.L., \& Frova, G. Uptake and elimination of enflurane in man. Brit. J. Anaesth. 44: 789 (1972).

16. Winters, W.D., Mori, K., Spooner, C.E., \& Bauer, R.O. The neurophysiology of anaesthesia. Anaesthesiology 26: 65 (1967).

17. Winters, W.D., More, K., Wallach, M.B., Marcus, R.J., \& Spooner, C.E. Reticular multiple unit activity during a progression of states induced by CNS excitants. Electroenceph. Clin. Neurophysiol 27: 514 ( 1969).

18. Winters, W.D., Ferrar-Allado, T., Guzman-Flores, C., \& Alcaraz, M. The cataleptic state induced by ketamine: a review of the neuropharmacology of anaesthesia, Neuropharmacology 11: 303 (1972).

19. WINTERs, W.D. Epilepsy or anaesthesia with ketamine: editorial views, Anesthesiology 36: 309 (1972).

20. Domino, E.F. The pharmacological analysis of the functional relationship between the brain stem arousal and diffuse thalamic projection systems. J. Pharmacology 115: 449 (1955).

21. Domino, E.F., Fox, K.E., \& Brody, T.M. Pharmacological actions of a convulsant barbiturate sodium 5-ethyl-5-( 1,3 dimethylbutyl) barbiturate I. stimulant and depressant effects. J. of Pharmacology 114: 473 (1955).

22. Domino, E.F. Pharmacological actions of convulsant barbiturate II. Effects compared with pentobarb on cerebral cortex and some brain stem systems of the cat. J. of Pharmacology 119: 272 (1959).

23. Goomman, L.S. \& Gilman, A. The pharmacological bases of therapeutics. 4th ed. The Macmillan Company, Toronto, Canada (1970).

24. Gumpert, J. \& PAUL, R. Activation of the electroencephalogram with intravenous brietal (methohexitone): the findings in 100 cases. J. of Neurol,, Neurosurg., Psychiat. 34:646 (1971).

25. Barkon, D.W. Propanidid in epilepsy. Anaesthesia 29: 445 (1974).

26. Garattini, S., Mussini, E., \& Randall, L.O. The benzodiazepines: monographs of the Maris Negri Institute for Pharmacological Research. 1st ed. Raven Press, New York (1973).

27. Lambroso, C.T. Treatment of status epilepticus with diazepam. Neurology 16:629 (1966).

28. LANOIR, J. \& KILlaM, E.K. Alteration in the sleep wakefulness patterns by benzodiazepines in the cat. Electroenceph. Clin. Neurophys. 25: 530 (1968). 
29. Kayama, Y. \& Iwama, K. The EEG, evoked potentials, and single unit activity during ketamine anaesthesia in cats. Anesthesiology 36:316 (1972).

30. Lebowitz, M.H., BurT, C.D., \& WaLrS, L.F. Depression of twitch response to stimulation of the ulner nerve during ethrane anaesthesia in man. Anesthesiology 33: 52 (1970).

31. Wollman, H., Simth, A.L., \& Hoffman, J.C. Cerebral blood flow and oxygen consumption in man during EEG seizure patterns induced by anaesthesia with ethrane. Proc. Fed. Am. Soc. Exp. Biol. 28; 356 (1969).

32. Michenfelder, J.D. \& Cucchiara, R.F. Canine cerebral oxygen consumption during enflurane anaesthesia and its modification during induced seizures. Anesthesiology 40: 575 (1974).

33. Evans, D. Anaesthesia and the epileptic patient. Anaesthesia 30: 34 (1975).

34. Gastaut, H. \& Broughton, R. Epileptic seizures: clinical and electrographic features, diagnosis and treatment. 1st ed. Charles C. Thomas, Springfield, Ill. U.S.A. (1972). 